ANUARIo DE Estudios MEDIEVAles (AEM)

36/2, julio-diciembre de 2006

pp. 783-801

ISSN 0066-5061

\title{
LOS BANDOS NOBILIARIOS Y LA CARRERA POLÍTICA: ASCENSO Y PRIVANZA DE BELTRÁN DE LA CUEVA
}

\begin{abstract}
Resumen: En este artículo se analizan las relaciones, pactos, alianzas y conflictos nobiliarios que tuvieron lugar durante los reinados de Enrique IV y Reyes Católicos con el objetivo de explicar cómo influyeron éstos en la trayectoria vital y política de Beltrán de la Cueva, primer duque de Alburquerque.
\end{abstract}

Palabras clave: relaciones internobiliarias; Poder político; Beltrán de la Cueva.

\section{M a DEL PILAR CARCELleR CERVIÑo Universidad Complutense. Madrid}

\begin{abstract}
This article analyzes the noble relationships, pacts, alliances and conflicts during Enrique IV and Reyes Católicos' reings to explain how those had influence on the vital and politic trajectory of Beltrán de la Cueva, first duke of Alburquerque.
\end{abstract}

Keywords: Noble relationships; Politic power; Beltrán de la Cueva.

\section{SUMARIO}

1. Introducción. La conformación de las redes sociales: su importancia para el mantenimiento de una posición privilegiada.- 2. Beltrán de la Cueva y la configuración de su sistema de relaciones durante el reinado de Enrique IV: 2.1. El poder del parentesco. la importancia de la familia Mendoza. 2.2. La entronización de Alfonso y sus efectos sobre la división de la nobleza. 2.3. El punto de inflexión. La batalla de Olmedo y el problema sucesorio. 2.4. La toma de nuevas decisiones tras la muerte de Enrique IV.- 3. Hacia la consolidación de la posición alcanzada: el reinado de los Reyes Católicos.- 4. Conclusiones.

\section{INTRODUCCIÓN. \\ LA CONFORMACIÓN DE LAS REDES SOCIALES: \\ SU IMPORTANCIA PARA EL MANTENIMIENTO DE UNA POSICIÓN PRIVILEGIADA}

El trabajo que aquí se presenta tiene como objetivo el análisis de un aspecto esencial en la dinámica política y social de la nobleza: la inserción de sus miembros en las ligas o bandos nobiliarios que por determinadas circunstancias históricas, si se nos permite generalizar, han dado vida y sustento a la corte, a la institución monárquica y a su mismo grupo social. No obstante, no pretendemos exponer una teoría general sobre la sociabilidad y organización solidaria de la nobleza, sino que lo que pretendemos es aplicar toda esta información general a un caso concreto que pueda ilustrar de qué modo la división de aquélla en grupos de diversa opinión política influyó en 
determinados personajes, de tal modo que permitió a éstos instalarse en el ámbito cortesano, prosperar y perpetuar su linaje y fama dentro de la aristocracia. Es el caso particular de Beltrán de la Cueva, conocido principalmente por su presunta paternidad de la infanta Juana y por los escándalos que marcaron el reinado de Enrique IV; pero cuya trayectoria vital ha sido, pese a la trascendencia de estos hechos, bastante ignorada por los historiadores ${ }^{1}$.

Partimos de la idea de que la jerarquización social no garantizaba únicamente el orden establecido, puesto que su misma existencia y constitución se rompía en ocasiones, posibilitando los cambios y, con ellos, la aparición de elementos nuevos en los distintos escalafones de la sociedad. El establecimiento de vínculos y redes de parentesco, amistad, clientelismo... era una vía para el ascenso, toda vez que un garante para el mantenimiento y la promoción dentro del grupo social al que se aspiraba a pertenecer o del que ya se era miembro. Por otra parte, los modos por los que se establecían estos vínculos eran muy diversos y, por lo que respecta a la nobleza, han sido objeto de estudios a los que, por exigencias de espacio, remitimos ${ }^{2}$.

Efectivamente, en el caso de la nobleza, como ha señalado Quintanilla Raso, «la capacidad de articular en torno suyo un entramado de vínculos personales, con diversos objetivos, constituía algo esencial en la caracterización de la jerarquía nobiliaria $»^{3}$. La unión, el acuerdo, el pacto verbal o escrito, fundamentaban sus relaciones y permitían establecer unas pautas comunes de actuación, sobre todo en los momentos de conflicto. A su vez, movilizaban a toda la sociedad, puesto que a sus redes horizontales se unían las verticales, aquellas que iban desde la cúspide de la nobleza a las clientelas establecidas en el ámbito de la corte y en el local, alejadas de aquélla. La propia familia, que determinaba de por sí la vinculación a un grupo concreto, procuraba también el posicionamiento de aquellos que vivían en su ámbito de influencia; predeterminaba generalmente el grupo en el que

${ }^{1}$ Hemos de destacar los trabajos pioneros de A. RodRíGUEZ VILLA, Bosquejo historiográfico de don Beltrán de la Cueva, primer duque de Alburquerque, Madrid, 1881 y el más reciente trabajo de A. FRANCO SILVA, Estudios sobre don Beltrán de la Cueva y el ducado de Alburquerque, Cáceres, 2002. Con el objetivo de paliar el abandono de este personaje se realizo la memoria de licenciatura de M. P. CARCELLER CERVIÑO Diego Enríquez del Castillo y la tratadística caballeresca en el siglo XV: «De re militari» de Paris de Puteo que fue léída el 1 de marzo de 2000 y la tesis doctoral defendida en juli de 2006 , Realidad y representación de la nobleza castellana del siglo XV: el linaje de la Cueva y la casa ducal de Alburquerque.

${ }^{2}$ Destacamos los trabajos de M.A. LADERO QUESADA, Linajes, bandos y parcialidades en la vida política de las ciudades castellanas (ss. XIV y XV), en Bandos y querellas dinásticas en la España al final de la Edad Media París 1991 pp 105-134, y de E. MITRE FERNÁNDEZ Crisis y "legitimaciones" dinásticas en la Peninsula a fines del siolo XIV ibídem, pp 37-58. Recomendamos, asimismo, los trabajos expuestos en la «XI Semana de Estudios Medievales de Nájera, 2000»: La familia en la Edad Media, J.I. de la Iglesia Duarte (dir.), Logroño, 2001.

${ }^{3}$ M.C. QuinTANILla Raso, Sociabilidad nobiliaria y solidaridad jerárquica en la Castilla del siglo XV, "Cuadernos de Historia de España», LXXVI (2000), p. 155. Véanse también: Les confedérations de nobles et les bandos dans le Royaume de Castille au Bas Moyen Age. ciudadana y jerarguización del poder. Bandos y parciálidades en Cuenca, "En la España ciudadana y jerarquización del poder. Bandos y parcialidades en Cuenca, «En la España de la Edad Media a la Modernidad, en J. Alvarado (coord.), Poder, economía, clientelismo, Madrid, 1997, pp. 15-49. 
el noble se integraba y con cuyos intereses estaba identificado. Por otro lado, la amistad o simplemente los intereses políticos, sociales o económicos eran otros factores que entraban en juego a la hora de establecer cualquier tipo de vínculo.

No obstante, como ha destacado López Benito, la nobleza de finales del siglo XV carecía de un programa político ${ }^{4}$. Como veremos, aquélla se amoldaría a las circunstancias históricas, y sobre la base de las posibilidades que éstas le ofreciesen, y sobre todo el grado de participación que le permitiese la autoridad monárquica, actuaría. Sólo tenía que estimar qué actitud era más conveniente para alcanzar sus objetivos. Por eso eran tan comunes los cambios de bando, sobre todo de aquellos personajes que más tenían en juego, o simplemente las negociaciones y confederaciones ${ }^{5}$. No obstante, también se testimonian fidelidades que se mantuvieron incólumes, eso sí, hasta que surgía la posibilidad de un cambio más prometedor.

Por otra parte, el «agrupamiento» de la nobleza no sólo respondía a la identificación de sus miembros con una ideología o forma de actuar, sino también a un deseo de protección, de defensa mutua. La defensa de un grupo suponía la existencia de un enemigo común y, por lo tanto, el establecimiento de unas líneas de actuación contra él. Efectivamente, las confederaciones eran también desvertebradoras, puesto que eran producto de la conflictividad ${ }^{6}$.

Como expondremos a continuación, estas pautas de comportamiento fueron seguidas, naturalmente, por Beltrán de la Cueva y por aquellos otros nobles con los que estableció algún tipo de relación (mediante acuerdo, confederación, pacto, amistad, matrimonio...). La dilatada vida política del duque de Alburquerque nos obliga inevitablemente a resumir la secuencia de los acontecimientos que envolvieron los pactos y confederaciones, puesto que nuestro objetivo es analizar cómo la vinculación a uno u otro grupo, la conformación de determinadas ligas nobiliarias, determinaron la trayectoria vital y política de este personaje. Destacaremos, asimismo, quiénes fueron sus protagonistas, los cambios en sus actitudes y las causas e implicaciones de sus compromisos; muchos de los cuales pervivieron más allá de su existencia.

\footnotetext{
${ }^{4}$ C.I. LóPEZ Benito, Bandos nobiliarios en Salamanca, 1983, Salamanca, p. 24. ${ }^{5}$ Centrado en el reinado de Enrique IV destacamos: M.I del VAL VALDIVIESO, Los bandos
nobiliarios durante el reinado de Enrique IV, «Hispania», XXXV (1975), pp. 249-293 y D.C. MORALES MUNIZ, Las confederaciones nobiliarias durante la guerra civil de 1465, "Anuario de Estudios Medievales», 18 (1988), pp. 454-467.

${ }^{6}$ M.C. Quintanilla Raso, Sociabilidad nobiliaria y solidaridad, p. 174. 


\section{BELTRÁN DE LA CUEVA \\ Y LA CONFIGURACIÓN DE SU SISTEMA DE RELACIONES DURANTE EL REINADO DE ENRIQUE IV}

Como ha expuesto Val Valdivieso, durante el reinado de Enrique IV la nobleza mantuvo una pugna no sólo por alcanzar mejores concesiones y privilegios, sino también para mantener su posición y grado de influencia. El poder monárquico, a la vez que contestado y menospreciado, iba ganando terreno y la nobleza no podía más que adaptarse a las nuevas condiciones sociopolíticas que iban aconteciendo ${ }^{7}$. Serían los sucesos de 1464, cuando esta pugna se hizo más patente para no concluir hasta finalizado este reinado, los que marcarían para Beltrán de la Cueva el inicio de su posicionamiento y su enfrentamiento con unos u otros grupos nobiliarios.

Como ya hemos indicado, el agrupamiento de la nobleza en bandos en los momentos más conflictivos era la plasmación de las alianzas por cuestiones políticas, de parentesco y clientelares. Como podremos apreciar, en el caso del primer duque de Alburquerque, política y parentesco van a jugar un papel relevante: los ataques de la nobleza rebelde y sus sucesivos matrimonios van a encauzar sin lugar a dudas su posición y actuaciones.

\subsection{El poder del parentesco: la importancia de la familia Mendoza}

El ingreso de Beltrán de la Cueva en la familia Mendoza, a través de su matrimonio en 1462 con Mencía, hija del marqués de Santillana, marcaría todas sus actuaciones posteriores: su círculo de influencias, sus pactos, sus decisiones políticas, la conformación de su patrimonio y su comportamiento en los años finales del reinado de Enrique IV y durante el de los Reyes Católicos. De hecho, no podemos desvincular los éxitos del duque de Alburquerque de su enlace con este poderoso linaje; lo cual no quiere decir, desde luego, que su unión a él fuese el único factor que determinó la posición que alcanzó en la corte.

No obstante, cuando Beltrán de la Cueva entró al servicio del rey, en la corte se producían transformaciones, pues no hacía mucho que Enrique IV había ocupado el trono castellano y la nobleza se acomodaba a la nueva situación. Para empezar, los Mendoza se enemistaron con el monarca, cuando anteriormente le habían apoyado frente a Álvaro de Luna ${ }^{8}$. Aunque tras la

\footnotetext{
255.

${ }^{7}$ Esta opinión de M.I. del VAL VALDIVIESO queda recogida en Los bandos nobiliarios, p.

${ }^{8}$ Véase L. SUÁREZ FERNÁNDEZ; A. CANELlas LóPEZ; J. VICENS VIVES, Caída y muerte de don Alvaro de Luna, en Historia de España, R. Menéndez Pidal y J. M. Jover (dirs.), t. XV: Los Trastámaras de Castilla y Aragón en el siglo XV, pp. 208, 212-213.

ANUARIO DE ESTUDIOS MEDIEVALES (AEM), 36/2, julio-diciembre 2006, pp. 783-801. ISSN 0066-5061
} 
muerte de Juan II acataron al nuevo soberano ${ }^{9}$, sus relaciones se torcieron ${ }^{10}$ y Enrique IV decidió arrebatar a Íñigo López de Mendoza la ciudad de Guadalajara, haciéndose inevitable su distanciamiento ${ }^{11}$. Pinel Monroy señala que Andrés Cabrera fue el intercesor entre el rey y los Mendozas para hacer las paces ${ }^{12}$. Efectivamente, la documentación demuestra los acuerdos que con esta intención se llevaron a cabo en $1461^{13}$.

La vuelta a la normalidad en sus relaciones hizo posible, primero, la devolución de la ciudad de Guadalajara y, segundo, que fracasado el intento de emparentar a Beltrán con Per Afán de Ribera, pudiese el monarca concertar el matrimonio de su favorito con esta poderosa familia. Hemos de incidir en el hecho de que Beltrán ya había adquirido una posición de influencia en el ámbito cortesano, es decir, su cercanía al rey había venido determinada, entre otras cosas, al encanto y servicio de un muchacho con fortuna. El que el monarca hubiese conseguido su enlace con los Mendoza es una prueba de ello. Este acontecimiento le permitiría, primero, consolidar la posición alcanzada $\mathrm{y}$, segundo, ascender social y económicamente. Los Mendoza le aseguraron interesantes, contactos y protección en los tiempos venideros; a partir de entonces Beltrán siempre se situaría en el grupo nobiliario en el que se encontrasen ellos, incluso cuando Enrique IV falleció y tuvo que tomar partido por Juana o por Isabel ${ }^{14}$. Además, la dote de Mencía le reportaba la villa fronteriza de Huelma, que durante un tiempo vendría a disfrutar Diego de la Cueva, padre de Beltrán, hasta 1472. El año de su desposorio le fue concedido, además, el condado de Ledesma, entrando a pertenecer a la nobleza titulada.

Por otra parte, como muestra de que la unión a un determinado grupo nobiliario tenía sus efectos desvertebradores, Beltrán ganaría también enemigos en la corte, entre los que se encontraría Juan Pacheco, su hermano Pedro Girón y aquellos que tuviesen con ellos lazos de algún tipo. Si bien

${ }^{9}$ Documentamos a algunos de sus miembros sirviéndole en la primera campaña granadina (Íñigo López de Mendoza y sus hijos) y en la embajada a Pío II (el mismo Iñigo Lopez). D pp. 150 y 65 .

${ }^{10}$ En 1456 el arzobispo Alonso Carrillo e Íñigo López de Mendoza, marqués de Santillana, hicieron pleito homenaje y se prometieron ayuda mutua contra el rey u otras personas que quisiesen hacerles daño. Véase el documento fechado el 22 de diciembre de 1456, AHN Nobleza, Osuna, leg. 1860, n. $^{\circ} 8$.

${ }^{11}$ Véase D. ENRÍQUEZ DEL CASTILLO, Crónica de Enrique IV, pp. 171-172 y F. PINEL Monroy, Retrato del buen vasallo. Copiado de la vida y hechos de D. Andrés de Cabrera, Primero marqués de Moya, ed. facsímil, 1983, p. 55.

${ }^{12} \mathrm{El}$ acontecimiento lo sitúa en 1461, F. PINEL MonRoy, Retrato del Buen Vasallo, p. 59.

${ }^{13} \mathrm{La}$ carta por la que el rey dio seguro a don Diego Hurtado de Mendoza, marqués de Santillana, con la promesa de proteger su persona, bienes y estado, se conserva en AHN Nobleza, Osuna, leg. 1860, no ${ }^{\circ} 10$. El poder que Enrique IV entregó a Juan Pacheco y al comendador Juan Fernández Galindo para tratar y concertar lo conveniente a la paz y sosiego del reino con el arzobispo de Toledo, el almirante don Fadrique, el conde de Alba, el conde de Paredes, el conde don Enrique, el marqués de Santillana y con los obispos de Coria y Calahorra, en Aranda, 5 de mayo de 1461, AHN, Secc. Nobleza, Frías, 9/1.

${ }^{14}$ En palabras de M.C. QUINTANILLA RASO, «la relación matrimonial, en cualquier caso, se convertia en el sustrato básico de una de las claves de articulación integradora de los nobles...» (Sociabilidad nobiliaria y solidaridad, p. 169). 
otros favoritos del monarca, desplazados por el ascenso de Beltrán, le tomaron inquina -el caso de Gómez de Cáceres-, no sucedió tal cosa a Miguel Lucas de Iranzo, quizá el más perjudicado por la carrera de Beltrán en la corte. El condestable, sin embargo, sería un importante apoyo del conde de Ledesma en Jaén, quizá debido al recuerdo que las actuaciones de Pacheco contra él le habían dejado por el tema de la concesión maestrazgo de Santiago, que a punto estuvo Enrique IV de entregar al giennense.

En los dos años que mediaron desde el enlace con Mencía hasta 1464, el conde de Ledesma aumentó su privanza sobre el rey, lo que se interpretó como un secuestro de la voluntad del soberano. La concesión del maestrazgo de Santiago era para don Enrique un merecido premio al conde por sus servicios, pero fue lo que hizo estallar a un sector de la nobleza. Como resultará obvio, el análisis de los acuerdos y solidaridades se multiplicaron durante este año, ofreciéndonos información abundante sobre el sentir de la nobleza. La situación de abandono y desgobierno denunciada por algunos nobles polarizó a este grupo social en dos y Beltrán de la Cueva, en el ojo del huracán, no pudo por menos que situarse en uno de ellos. Fueron pactos colectivos, de nobles unidos por una causa común que se levantaron y trataron de imponer sus reglas al monarca y al grupo que le era fiel; pero sobre todo al conde de Ledesma, al que pretendieron eliminar de la escena política.

Juan Pacheco y su hermano Pedro Girón serían, junto con el arzobispo de Toledo, que antes tan buenos entendimientos había tenido con los Mendoza, los primeros en movilizarse ${ }^{15}$. Las acusaciones, por otra parte, no sólo iban destinadas a Beltrán sino también a sus «parciales». Para empezar buscaron el apoyo del rey, la reina y el príncipe de Aragón, pendientes éstos del futuro de la corona castellana ante las acusaciones vertidas contra el monarca, su esposa y la pequeña Juana ${ }^{16}$. A su lado se alinearon también el arzobispo de Toledo, los condes de Benavente, Salinas, Paredes, Alba ${ }^{17}$, Plasencia, los Manriques y el almirante ${ }^{18}$. Uno de los documentos más representativos y más conocidos de este periodo es el emitido en Burgos por la hermandad de nobles, que se habían reunido en la ciudad castellana para solventar los problemas del reino, y en el cual se denunciaba que

[...] las cosas han ydo de mal en peor como por esperençia paresçe, espeçialmente porque el conde de Ledesma se ha apoderado de la persona del dicho señor rrey e del bien común de sus rregnos yrían en final detruyçión $[\ldots]^{19}$.

\footnotetext{
${ }^{15}$ Recordemos la carta en la que los tres denunciaban el secuestro del rey y los infantes de mayo de 1464, en BN, ms. 13.109.

${ }^{16} 23$ de mayo de 1464 , R. PÉREZ BuSTAMANTE, Enrique IV. 1454-1474, colec. Corona de España. Reyes de Castilla y León, XI, Burgos, 1998, p. 159.

${ }^{17}$ Véase la confederación del conde de Alba con Juan Pacheco firmada el 7 de agosto de 1464, en D.C. MORALES MuÑZ, Las confederaciones nobiliarias en Castilla, p. 462.

${ }^{18}$ Véase el acuerdo firmado el 16 de julio de 1464 en Tárrega, documentado por F. PINEL Y MONROY, Retrato del Buen Vasallo, pp. 72-73.

${ }^{19}$ La carta podría fecharse en mayo de 1464, AHN, Secc. Nobleza, Frías, 16/15. 
La situación política del reino se vio igualmente reflejada en el ámbito giennense, en especial en la ciudad natal de Beltrán de la Cueva. Gómez de Cáceres colaboró en la toma de Úbeda por el maestre de Calatrava, mientras que Lucas de Iranzo colaboró con la familia del conde en su defensa ${ }^{20}$. La división del reino se vio reproducida a pequeña escala en la ciudad natal del de la Cueva, donde los Molina, contrarios a este linaje, se acogieron a la causa de Girón y Pacheco. Esto constituye un magnífico ejemplo de cómo las alianzas de los nobles se transmitían y contagiaban a todos aquellos con los que mantenían vínculos por intereses de algún tipo, en este caso de la cúspide a la media y baja nobleza ciudadana.

No obstante, la lista de apoyos de Beltrán era importante: aparte de ser favorecido por el reconocimiento de monarcas extranjeros, como el inglés Eduardo IV, quien le felicitó por la obtención de la dignidad de maestre ${ }^{21}, \mathrm{y}$ el portugués Alfonso V, quien alabó las facultades diplomáticas del conde de Ledesma $^{22}$, gozaba del apoyo de la nobleza fiel a Enrique IV. Su familia política, los Mendoza, estaba representada por Pedro González de Mendoza, obispo de Calahorra, y su hermano Diego Hurtado de Mendoza, marqués de Santillana y suegro de Beltrán. También le apoyaban Pedro de Velasco, hijo del conde de Haro, Lorenzo, vizconde de Torija y Gonzalo de Saavedra, comendador mayor de Montalbán ${ }^{23}$.

Pese a las graves acusaciones que se vertieron contra Beltrán de la Cueva, el castigo que la nobleza rebelde logró arrancar del monarca no fue muy duro, principalmente porque habían obtenido la aprobación de la sucesión de Alfonso. El conde de Ledesma debió marchar de la corte, pero se le entregaron a cambio importantes villas, entre ellas Cuéllar y Alburquerque, esta última con el título de ducado. En su castigo se vieron arrastrados personajes menos conocidos, presuponemos que vinculados a Beltrán por lazos de clientelismo, y que aparecen en la lista de los desterrados: Alfonso de Badajoz, secretario del rey, Garcí Méndez de Badajoz, Fernando de Badajoz, Alfonso de Torres y Alfonso de Herrera. Entre los expulsados también se encontraba el obispo de Calahorra ${ }^{24}$.

Así pues, en este año de 1464 un grupo nobiliario, encabezado por los Mendoza, arropó a Beltrán de la Cueva, mientras que otro grupo le denostaba. No obstante, los intereses particulares primaban sobre el bienestar común,

\footnotetext{
${ }^{20} \mathrm{~J}$. de M. CARriazo (ed.), Hechos del Condestable Miguel Lucas de Iranzo, Madrid, 1940 pp. 253-255.

${ }^{21}$ En una carta fechada el 28 de octubre de 1464, ACDA, No 4, C. ${ }^{a} 4, n^{\circ} 26$. 199.

${ }^{22}$ Véanse los comentarios que sobre este hecho se recogen en Hechos del condestable, p.

${ }^{23}$ Como ejemplos: RAH, Col. Salazar, 9/412, fols. 119-120; AGS, Patronato Real, leg. 7, fol. 111; AHN, Secc. Nobleza, Frías, 9/24. Como aseguradores del cumplimiento dẹl acuerdo de expulsión de don Beltrán aparecen el marqués de Villena, el conde de Plasencia, por un lado, y presumiblemente (porque no se menciona expresamente) en el otro el comendador Gonzalo de Saavedra y don Pedro de Velasco. Consúltense AHN, Secc. Nobleza, Frías, 9/24 y 9/4 y Memorias de don Enrique IV de Castilla, vol. II, RAH, Madrid, 1835-1913, n ${ }^{2} \mathrm{CV}$.

${ }^{24} \mathrm{La}$ expulsión se decretó finalmente el 12 de diciembre de 1464, AHN, Secc. Nobleza, Frías, 9/4. Acerca del papel de este obispo en estos acontecimientos yéase J.M. NIETO SORIA, Iglesia y génesis del Estado Moderno en Castilla. 1369-1480, Madrid, 1993, p. 279.
} 
siendo la toma del control del poder lo que les movía a ambos; unos arropando a Enrique IV, toda vez que defendían a su última apuesta, el conde de Ledesma; otros reclamando la sucesión del infante Alfonso, del que pretendían obtener lo que Enrique IV les negaba.

\section{la nobleza}

2.2. La entronización de Alfonso y sus efectos sobre la división de

El alejamiento del duque de la corte no duró mucho, pues el descontento y la división de la nobleza no habían conseguido solventarse con los acuerdos firmados a finales del año anterior. Enrique IV expidió el seguro para que Beltrán y los suyos regresasen sin ningún contratiempo ${ }^{25}$.

En la nobleza no se produjeron cambios de opinión de relieve, y los opositores de Beltrán de la Cueva continuaron siendo los mismos. No obstante, sí se aprecian actitudes diferentes en aquellos que actuaron como aseguradores de los pactos del año anterior: es el caso de Pedro de Velasco y Gonzalo de Saavedra, que firmaron un acuerdo para que el duque devolviera la villa de Cuéllar a la infanta Isabel ${ }^{26}$.

La gestación de la Farsa de Ávila también se puede intuir en las alianzas que se iban urdiendo con el fin de desplazar a los enemigos y alcanzar los beneficios más codiciados cuando ellos mismos alzaran al infante como rey $^{27}$. A Pacheco se uniría el comendador Gonzalo de Saavedra, al que vemos definitivamente cambiar de signo ${ }^{28}$, pero el hijo del conde de Haro, pese a que también suscribió la devolución de Cuéllar, se mantendría en el grupo enriqueño y como aliado del duque.

Por lo que respecta a los partidarios de Beltrán de la Cueva, encontramos nuevos personajes. Es el caso del conde de Medinaceli, Luis de la Cerda, señor de la villa del Puerto de Santa María, con quien el duque firmó un pacto de ayuda y defensa mutuas. Un acuerdo posterior, en el que se establece un intercambio de villas, puede darnos la pista de los intereses que a ambos personajes movían a la hora de firmar esta escritura ${ }^{29}$. En esta

\footnotetext{
${ }^{25} \mathrm{ACDA}, \mathrm{N}^{\mathrm{o}} 6, \mathrm{C}^{\mathrm{a}} 6, \mathrm{n}^{\mathrm{o}} 4$. Véase también la petición de los procuradores del reino, hecha en Cortes, a favor del duque de Alburquerque, realizada en Salamanca, el 26 de mayo de 1465 , conservada en ACDA, $\mathrm{N}^{\circ} 6, \mathrm{C}^{\mathrm{a}} 6, \mathrm{n}^{\circ} 12$.

${ }^{26} 16$ de enero de 1465, AGS, Patronato Real, leg. 32, fol. 4.

${ }^{27}$ Pongamos como ejemplo los acuerdos que Juan Pacheco y Álvaro de Estúñiga firmaron con Rodrigo Pimentel, duque de Benavente, en los que le prometían su apoyo cuando la coronación de Alfonso fuera una realidad y pudiera obtener la ciudad de Toro. AHN, Nobleza,
Osuna, leg. $417, \mathrm{n}^{\circ} 7$.

${ }^{28}$ Sobre la división del reino en la Farsa de Ávila véase M.I. del VAL VALDIVIESO, Los bandos nobiliarios, pp. 252 ss. Sobre este tema ha continuando la investigación la tesis de Shima OHARA, La propaganda política en torno al conflicto sucesorio de Enrique IV. 1457 1454. Las estructuras de la suplicación como sistema político, «poder informal en la Corona de Castilla a fines del siglo XV, dirigida por M.I. del Val, Universidad de Valladolid, 2004. Recuérdese que don Beltrán vendió Saja a Gonzalo de Saavedra el 25 de abril de 1461 (RAH, Col. Salazar y Castro, 9/811, fol. 139v.).

${ }^{29} \mathrm{El} 22$ de mayo del año siguiente de 1466 ambos acordaron el trueque de la villa de Molina, su tierra y alcázar, por Santa María del Puerto y Cogolludo, sus fortalezas y tierras. ACDA, $\mathrm{N}^{\mathrm{o}} 6, \mathrm{C}^{\mathrm{a}} 6, \mathrm{n}^{\mathrm{o}} 14 \mathrm{y} \mathrm{N}^{\mathrm{o}} 7, \mathrm{C}^{\mathrm{a}} 7, \mathrm{n}^{\mathrm{o}} 17$. 
ocasión se superponían de nuevo los vínculos de parentesco, porque Beltrán excluía al marqués de Santillana y descartaba cualquier actuación en su contra $^{30}$. Otro pacto de amistad fue firmado por el duque de Alburquerque, el obispo de Calahorra y el conde de Alba con el duque de Feria, con el que prometieron colaborar en la defensa de Enrique IV $^{31}$.

En los acuerdos que ambos bandos intentaron alcanzar, el de la Cueva, antes protagonista de relevantes encuentros políticos, se abstuvo de participar, quizá porque hubiera sido contraproducente que se presentara como intermediario aquel a quien se le acusaba de desencadenar el conflicto. El elegido fue el marqués de Santillana, quien podía, por otra parte, garantizar la seguridad y estabilidad de su yerno ${ }^{32}$. El protagonismo político de Beltrán se iba, de esta manera, apagando, pero sólo aparentemente.

Quizá una de las confederaciones más interesantes de los años que van de 1464 a 1468 es la firmada en 1466, cuando la maltratada reina Juana tomó las riendas de la política y en nombre de su marido reunió a sus parciales para asentar un pacto de amistad, de ayuda y defensa por una causa común ${ }^{33}$ :

\begin{abstract}
Conosçida cosa sea a todos los que la presente vieren como yo, doña Juana, por la gracia de Dios rreyna de Castilla e de León, porque entyendo que así, conplidero al seruiçio de Dios e del rrey mi señor e mío e al bien e paçífico estado destos rregnos tomar e ayuntar al seruiçio del dicho rrey mi señor e mío algunos perlados y caualleros e otras personas e fazer con ellos algunas ligas e confederaçiones de que se espera seguir grand seruiçio del dicho señor rrey e grand bien de los fechos presentes. Por ende, por la presente, tomo e rreçibo por espeçiales seruidores e amigos a don Beltrán de la Cueua, duque de Alburquerque, conde de Ledesma, e a don García Áluarez de Toledo, conde de Alua, señor de Villacorneja, e a don Pedro González de Mendoça, obispo de Calahorra; e fago amistad, liga e confederaçión con todos vosotros e con cada vno de vos e seguro e prometo que guardaré e seré en guardar e defender vuestras personas y onrras e casas e estados e dignidades e patrimonios, çibdades e villas e logares, heredades e vasallos e otras qualesquier cosas que agora tenedes todos e cada vno de vos e touiedes e vos perteneçen o perteneçieren [...].
\end{abstract}

La confederación se anteponía a cualquier otra pactada por los participantes en ella y no tenía en cuenta la dignidad o el estado del enemigo para actuar contra él. A la promesa de Juana seguían la de los nobles implicados que se comprometían a tenerla por señora y a responder por ella por el bien del reino, estableciendo un vínculo que iba más allá de la amistad, instituyendo un lazo de parentesco indisoluble «como buenos e verdaderos

\footnotetext{
${ }^{30} 12$ de febrero de 1465, Roa, ACDA, No $6, \mathrm{C}^{\mathrm{a}} 6, \mathrm{n}^{\mathrm{o}} 4$.

${ }^{31} \mathrm{RAH}$, Col. Salazar, 9/812, 253v-254.

${ }^{32}$ Como representante del bando contrario fue elegido el conde de Plasencia. Como aseguradores de los acuerdos se presentaron el arzobispo de Toledo, el conde Enrique, el almirante y el conde de Benavente (Arévalo, 8 de octubre de 1465. AHN, Secc. Nobleza, Osuna, leg. 1860, $\mathrm{n}^{\circ} 12$ ).

${ }^{33}$ Nobleza, Osuna, leg. 1860, $\mathrm{n}^{\mathrm{o}} 15^{2}$. Este documento se complementa con la confederación de los nobles mencionados en la firmada con la reina, que particularmente redactaron otra en el mes de marzo con las mismas condiciones. AHN, Secc. Nobleza, Osuna, leg. 1860, $\mathrm{n}^{\circ} 16$. 
hermanos, parientes e amigos e confederados». A este pacto se añadieron seguidamente acuerdos independientes, como el establecido entre Beltrán y el conde de Alba del mismo tenor que el anterior ${ }^{34}$, o el firmado entre estos dos personajes y el obispo de Calahorra ${ }^{35}$. Por lo que respecta al conde de Alba, su compromiso con el bando enriqueño no fue definitivo, puesto que, como señala Morales Muñiz, su posicionamiento vendría determinado por la voluntad de cada uno de los monarcas de cumplir con sus demandas, principalmente la merced de Ciudad Rodrigo ${ }^{36}$.

Sin embargo, todos los intentos de conciliación fueron infructuosos y a finales de año se pactó la entrega de la reina Juana como rehén, curiosamente cuando ésta concedía a Juan Pacheco un seguro ${ }^{37}$. Beltrán de la Cueva optó por alejarse de nuevo de la corte. Pese a estar arropado por una parte de la nobleza, su situación se hacía cada vez más inestable y el grupo contrario a él lograba arrancar al monarca decisiones que podían terminar perjudicándole en mayor medida que un destierro voluntario. No obstante, éste fue breve, puesto que su servicio era necesario a don Enrique; pero quizá previendo las consecuencias que su regreso podía acarrearle, estableció un sorprendente pacto con su mayor enemigo, el marqués de Villena: una alianza matrimonial por medio de sus hijos que nunca llegaría a materializarse ${ }^{38}$. sucesorio

\subsection{El punto de inflexión: la batalla de Olmedo y el problema}

Desde que en 1464 estallara el conflicto, los grupos nobiliarios estaban muy definidos y las defecciones no fueron comunes. Igualmente, se iban estableciendo las líneas de actuación futuras por ambos lados, no sólo mediante los acuerdos que hemos enumerado, sino también por sus actitudes y por las razones que movieron a establecer esos pactos. En el bando rebelde a Enrique IV, la oposición al gobierno del monarca y a sus colaboradores determinaron sus acciones y su oposición constantes. El infante Alfonso les permitía crear una nueva corte y establecer sus propios lazos e influencias, así como obtener mercedes que Enrique IV había postergado. En el bando proenriqueño a los nobles les unía la fidelidad a un monarca que, por otra parte, cumplía con sus expectativas y sus ambiciones. Entre ellos establecieron lazos sólidos, reforzados en muchos casos por el parentesco. Es ya

\footnotetext{
${ }^{34}$ Firmado el día 7 de marzo de 1466, en ACDA, N. ${ }^{\circ}$ 6, Ca $6, n^{\circ} 4$. D.C. MORALES MuÑIZ nos da testimonio de la confederación particular establecida entre el conde de Alba y la reina Juana y entre ésta y el marqués de Santillana. Por otra parte, el día 3 de enero de 1466, el marqués de Santillana otorgo poder a su secretario, Diego García de Guadalajara, para que se confederara en su nombre con cualquier persona, incluidos los reyes. D.C. MORALES MUNIZ Las confederaciones nobiliarias en Castilla, $\mathrm{p}$. 460 . Un poder similar concedería Beltrán el 29 de agosto al comendador Pedro de León, para que hiciera en su nombre las alianzas y gestiones convenientes. AHN, Secc. Nobleza, Osuna, leg. 1860, $n^{\circ} 14$.

${ }^{35}$ R. Pérez Bustamante y J.M. Calderón Ortega, Enrique IV, p. 200.

${ }^{36}$ D.C. MORALES MuÑIZ, Las confederaciones nobiliarias en Castilla, p. 463.

${ }^{37}$ Coca, 4 de noviembre de 1466, AHN, Secc. Nobleza, Frías, 14/4.

${ }^{38}$ Establecido el mes de diciembre de 1466, AHN, Secc. Nobleza, Frías, 102/2. 
significativo que el conde de Alba y Pedro de Velasco se encuentren del lado de Beltrán de la Cueva, por cuanto ahora lo harán por amistad, deudo o por compartir las mismas ideas o aspiraciones, pero en un futuro emparentarán por vía matrimonial.

Por otra parte, la batalla de Olmedo supuso un punto de inflexión en el comportamiento de estos nobles. La indecisión del monarca tras la contienda determinó el alejamiento más prolongado de Beltrán de la corte y un cambio progresivo en la actitud de los Mendoza, que culminó con la aceptación de la sucesión de Isabel, arrastrando con ello a su grupo de influencia. Por otro lado, Pacheco, en un giro de 360 grados, volvió a la obediencia de Enrique IV, abocando a su primogénito al enfrentamiento con Isabel y Fernando tras la muerte del monarca.

Durante 1467 las noticias sobre acuerdos y confederaciones son abundantes. Es el caso del conde de Benavente, Rodrigo Pimentel, que mantuvo conversaciones con Pedro de Velasco y el propio Beltrán de la Cueva $^{39}$. Su posición, sin embargo, fue inamovible. Igualmente, el marqués de Santillana, Pedro de Velasco y Beltrán estrecharían a su vez lazos entre sí y con el monarca, prometiéndose absoluta colaboración ${ }^{40}$. El marqués, además, establecería una confederación con el conde de Alba, pues, previendo el enfrentamiento, estimaron necesario reafirmarse en su amistad y buen entendimiento para que el resultado de la batalla no influyese en su alianza ${ }^{41}$.

En el momento en que Isabel comenzó a tomar decisiones, aun antes del fallecimiento de su hermano Alfonso, determinados nobles comenzaron a establecer vínculos y pactos con ella, puesto que su matrimonio era una baza importante en la que había que participar si se querían obtener beneficios políticos y personales ${ }^{42}$.

Tras morir el infante, y tras los acuerdos tomados por el monarca e Isabel en Casarrubios del Monte y el encuentro de los Toros de Guisando ${ }^{43}$, la aceptación de las condiciones impuestas por la nobleza hasta el momento proalfonsina creó confusión, lo que hace más difícil situar a los nobles en uno u otro bando. Así, Pacheco de nuevo se acercó al rey; reconciliación de la que obtendría su tan ambicionado maestrazgo de Santiago. Por su parte Beltrán de la Cueva llegó a acuerdos personalmente con otros nobles, algunos con implicaciones en la política del reino en los años que median entre la promesa de Enrique IV de dejar el trono a Isabel y la muerte del monarca. Es el caso

\footnotetext{
${ }^{39}$ En Olmedo a 13 de julio de 1467, ACDA, N ${ }^{\circ} 6, C^{\text {a }} 6, n^{\circ} 4$. p. 213

${ }^{40} 6$ de agosto de 1467 , R. PÉrez Bustamante y J.M. CALderón OrTega, Enrique $I V$,

${ }^{41}$ La muestra de máxima confianza hacia el marqués de Santillana por parte del rey se demostró al aceptar el soberano que éste quedase con la custodia de su hija Juana. D.C. MORALES MUNIZ, Las confederaciones nobiliarias en Castilla, p. 462.

${ }^{42}$ Recordemos el acuerdo al que Carrillo, Pacheco y el duque de Alba, futuro suegro de Beltrán de la Cueva, llegaron con Isabel para que ésta pudiese intervenir en sus planes matrimoniales. L. SUÁREZ FERNÁNDEZ, Enrique IV de Castilla: la difamación como arma política, Barcelona, 2001, p. 380.

${ }^{43}$ Véanse las capitulaciones que se hicieron entre Enrique IV, la infanta Isabel y los grandes en: BN, ms. 13.109, fol. 199; AHN, Secc. Nobleza, Frías, 16/19 y AGS, Patronato Real, leg. 7, fol. 112 . 
del acuerdo que estableció con Fadrique, almirante de Castilla, por el que éste se comprometía a ayudar al duque contra cualquier persona que fuese contra él si la princesa Isabel marchase con los suyos para atacar Cuéllar. Con la misma intención pactó Beltrán con Pedro de Luna, copero del rey ${ }^{44}$. En este caso, las negociaciones sólo iban dirigidas por parte del duque a proteger su patrimonio, por lo que atañían a sus intereses particulares, pero desde luego las otras partes tendrían sus propios objetivos. Es realmente extraño que el almirante firmase un pacto de ese tenor con Beltrán, por cuanto siempre había luchado en bando contrario, pero también es indicativo de la indecisión de este personaje en los primeros momentos en los que Isabel podía resultar, como Alfonso, sólo un proyecto.

En 1469 encontramos a Beltrán unido en una importante empresa con su tradicional aliado, Pedro de Velasco, y uno de sus enemigos hasta el momento, Rodrigo Pimentel. La situación del reino, ahora en tensión por la pujanza de Isabel, hacía necesario el reparto de las facultades de gobierno. Estos tres nobles recibirían el poder del rey para actuar en su nombre ${ }^{45}$, lo que revela la búsqueda de Enrique IV, y sobre todo de la nobleza, de un equilibrio en las fuerzas. Beltrán seguía representando para el monarca un hombre fiel que podía garantizar la defensa de sus derechos y el que aparezca en la documentación como virrey nos da noticia de un repunte de su actividad política tras los dos periodos de destierro que había sufrido. No en vano contaba con aliados de relieve, un patrimonio considerable, por las continuas mercedes recibidas, y un prestigio militar incuestionable ${ }^{46}$.

Los acuerdos entre nobles antes enfrentados que a partir de este momento se documentan se debieron, quizá, a la confusión, la indeterminación y la desconcertante evolución de los acontecimientos. Las decisiones tuvieron que ser pactadas, intentado alcanzar la mejor solución para un bando, el de Enrique IV, que ahora reunía a tradicionales enemigos en una empresa común: elegir al mejor candidato a la sucesión del trono castellano. De este modo, encontramos el compromiso alcanzado para el matrimonio de la infanta Juana por un grupo tan heterogéneo como el marqués de Santillana, el maestre de Santiago, el conde de Plasencia, el obispo de Sigüenza, Pedro de Velasco y el duque de Alburquerque ${ }^{47}$; la alianza del marqués de Santillana, el condestable Diego de Velasco y el obispo de Sigüenza con Juan Pacheco ${ }^{48}$; o la confederación establecida entre Enrique IV, el arzobispo de Sevilla, el maestre de Santiago y el conde de Plasencia, de una parte, y con

\footnotetext{
${ }^{44}$ Acuerdos del 11 y el 18 de diciembre de 1468 respectivamente, ambos en ACDA, $N^{\circ} 6$, $\mathrm{C}^{\mathrm{a}} 6, \mathrm{n}^{\circ} 4$.

${ }^{45} \mathrm{AHN}$, Nobleza, Osuna, leg. 417, $\mathrm{n}^{\mathrm{o}} 15$; Memorias de don Enrique IV, $\mathrm{n}^{\mathrm{o}} \mathrm{CLXIV}$.

${ }^{46}$ Como virrey se le menciona en un documento expedido el 1 de agosto de 1469 , A. BARRIOS GARCÍA; F F LUIS DEL CORRAL; E. RIAÑO PÉREZ, Documentación medieval del Archivo Municipal de Mombeltrán, Fuentes históricas abulenses, 17, Avila, 1996, p. 218. Sobre la faceta caballeresca y militar de Beltrán de la Cueva se dedica un capítulo en Realidad y representación de la nobleza castellana, op. cit.

${ }^{47}$ Enero de 1469 , BN, micro CTD, caja 4, Res. 226(24).

${ }^{48}$ Ocaña, 15 de enero de 1469, AHN, Secc. Nobleza, Frías, 14/12. 
el marqués de Santillana y el duque de Alburquerque por la otra ${ }^{49}$. Todas ellas iban encaminadas, como hemos advertido, a la solución del conflicto dinástico a través de la toma de decisiones sobre el futuro de Isabel y de Juana, a la vez que mostraban su compromiso de mantenerse fieles a Enrique IV. Seguimos comprobando que Beltrán en ningún momento abandonó la posición de su suegro el marqués de Santillana, incluso cuando contrajo nuevo matrimonio y dejó de tener esa relación de parentesco.

También sería trascendental para el duque la solución del matrimonio de su primogénito con la hija del conde de Alba, con quien había sido compañero de bando intermitentemente ${ }^{50}$. Se unía así con una nueva casa con la que mantendría una vinculación que conduciría su posición política, aunque el peso de los Mendoza seguiría siendo determinante. El lazo con los Alba se vería más reforzado cuando el propio Beltrán casase con otra hija de García en 1476, al morir Mencía de Mendoza.

A partir de los años finales del reinado de Enrique IV, el bando proenriqueño se constituyó entonces con las figuras destacadas del maestre de Santiago, el marqués de Santillana, Pedro de Velasco, conde de Haro,el obispo de Sigüenza y sus parciales, entre los que naturalmente se encontraba el duque de Alburquerque; mientras que el bando contrario, el proisabelino, contaba, como principales apoyos, con el arzobispo de Toledo, el almirante -que recordemos que anteriormente había firmado en 1468 un acuerdo con Beltrán para ayudarle si los partidarios de Isabel atacaban Cuéllar- y el conde Diego Manrique ${ }^{51}$. Sin embargo, desde 1472 los Mendoza comenzaban a dar un giro en sus relaciones con los príncipes y el propio Beltrán se mostró ambiguo en los tratos con los partidarios de Juana y los partidarios de Isabel (Pacheco/Cabrera).

Efectivamente, estas alianzas en pro del bien del reino eran débiles cuando los asuntos personales se interponían. Así lo demuestra el enfrentamiento que el marqués de Santillana, apoyado por el conde de Treviño, Pedro Manrique, el duque de Alburquerque y el condestable, sostuvo con Rodrigo Pimentel, apoyado a su vez por Pacheco y el conde de Castro, por la villa de Carrión, antiguamente de los Mendoza y otorgada por Enrique IV al conde de Benavente ${ }^{52}$. En esta ocasión los Mendoza se enfrentaban a una decisión del monarca, y el apoyo de Beltrán a la causa de su familia representaba el mismo hecho.

Por otra parte, los asuntos personales también procuraron a Beltrán otra nueva alianza, la de Pedro de Monroy, comendador de Alcántara, cuando

\footnotetext{
${ }^{49} 18$ de marzo de 1469, AHN, Secc. Nobleza, Osuna, leg. 1860, no 20.

${ }^{50} 5$ de marzo de 1469 , ACDA, $\mathrm{N}^{\mathrm{0}} 242$, leg. $3, \mathrm{n}^{\circ} 8$.

${ }^{51}$ Así lo resume un documento hallado en AMU, leg. 2, $\mathrm{n}^{0} 11$.

${ }^{52}$ Sucedía esto en 1473, E. TORAL PeÑARANDA, Úbeda (1442-1510), Jaén, 1975, p. 145. La crónica de Diego Enríquez del Castillo coincide con la versión dada por este historiador (cap. 165, pp. 393 ss.), pero la Crónica anónima nọ, pues señala que el duque de Alburquerque (cap. 165, pp. 393 ss.), pero la Cronica anonima no, pues señala que el duque de Alburquerque
era partidario de Pacheco y el cardenal, por la amistad que a los tres les unía con el conde de
Benavente (Crónica anónima de Enrique IV de Castilla, 1454-1474, M. Pilar Sánchez Parra Benavente (Crónica anónima de Enrique IV de Castilla, 1454-1474, M. Pilar Sánchez Parra
(ed.), Madrid, 1991, p. 442). Nos inclinamos por la versión de Enríquez, puesto que el conde de Benavente había sido tradicional oponente de don Beltrán de la Cueva y Enrique IV. 
se desató la rebelión de Juan de Torres, alcaide de la fortaleza de Alburquerque $^{53}$. Piénsese que Pedro de Monroy estaba enemistado con Gómez de Cáceres por el maestrazgo de Alcántara y éste había sido contrario a Beltrán durante la polémica concesión del maestrazgo de Santiago de 1464. Las antiguas rivalidades podían ahora prevalecer y, por otra parte, ser aprovechadas para encontrar apoyos para causas particulares.

\subsection{La toma de nuevas decisiones tras la muerte de Enrique IV}

Como ya adelantamos, la evolución de los pactos y acuerdos establecidos a partir de 1468, así como el matrimonio de Isabel con Fernando afectarían notablemente al posicionamiento que la nobleza iría adoptando hasta que el ascenso de los Católicos al trono de Castilla fuese una realidad. Pacheco volvería a reconocer a Enrique IV y a unirse a los Mendoza y los suyos, mientras que otros que habían apoyado a Alfonso siguieron ahora a Isabel, como fue el caso del arzobispo Carrillo y el almirante. Beltrán, no se desgajó en ningún momento de los acuerdos firmados por los Mendoza, aun cuando el maestre de Santiago estuviese implicado.

En la propia corte encontramos de nuevo luchas por obtener la influencia y el control de la persona del monarca y Beltrán se verá de nuevo implicado en ello junto con el eterno Juan Pacheco y una tercera parte en discordia: Andrés de Cabrera. La posición ambigua del mayordomo en lo que se refiere a la sucesión favorecería también las informaciones tan contrarias que nos llegan sobre la relación de los tres personajes. La Crónica anónima es la que más noticias sobre ello nos aporta.

Por un lado, parece que Beltrán apoyó a Andrés de Cabrera con el objetivo de hacer sombra al maestre de Santiago ${ }^{54}$. Sin embargo, Juan Pacheco trató de ganarse la amistad del duque de Alburquerque al no estar de acuerdo con las intenciones del mayordomo, que deseaba la reconciliación del monarca con su hermana Isabel. Nada más lejos de los proyectos de Juan Pacheco ${ }^{55}$. Precisamente por estas fechas, según la Crónica anónima, el maestre de Santiago, en un acercamiento mayor al duque, le pidió que le dejara casarse en la villa de Cuéllar con una hija del condestable, la que años después sería esposa del propio Beltrán, María de Velasco ${ }^{56}$.

En un principio Beltrán colaboraría con Pacheco y junto con el cardenal idearían la toma de Segovia contra Cabrera ${ }^{57}$. Además, firmaría un acuerdo con el marqués de Villena por el que prometía hacerle pleito homenaje y negociar sobre la sucesión, sobre el matrimonio de Juana, así

\footnotetext{
${ }^{53}$ Véase documentación al respecto en ACDA, $\mathrm{N}^{\mathrm{o}} 6, \mathrm{C}^{\mathrm{a}} 6, \mathrm{n}^{\mathrm{o}} 6$.

${ }^{54}$ Crónica anónima, p. 249.

${ }^{55}$ Fue un legado papal quien, según del Pulgar, quiso reconciliar a Enrique IV con los príncipes y con Andres de Cabrera y su mujer. El maestre de Santiago marchó a Cuéllar para pactar con Beltrán la destrucción de Andrês de Cabrera. H. PÉREZ DEL PULGAR, Crónica de los Reyes Católicos, J. de M. Carriazo (ed.), vol. II, Madrid, 1943, p. $248 \mathrm{~b}$.

${ }^{56}$ Crónica anónima, p. 425.

${ }^{57}$ Crónica anónima, p. 445.
} 
como que no haría confederación con los reyes de Sicilia ni con otros de su partido $^{58}$. Esto hace más sorprendente la colaboración e incluso unión familiar que establecería en un futuro su hijo Francisco Fernández de la Cueva con el marqués de Moya por medio del matrimonio de sus hijos.

La oposición de Villena, por otra parte, contrasta con la fidelidad de Cabrera al rey Enrique, pero lo que separaba a ambos no era la opción monárquica de ese momento, sino la del futuro. A principios de 1474, Andrés de Cabrera firmaba una alianza con Rodrigo Pimentel, conde de Benavente, por la que ambos se comprometieron a servir a la persona de Enrique IV y defenderse mutuamente ${ }^{59}$. Sintomático de los cambios que habrían de venir con la muerte del monarca, el mismo conde de Benavente se confederaba después y prometía ayuda y defensa mutua con el cardenal, el condestable y el almirante con la promesa de ser fieles a Isabel y Fernando. Dejaban una cláusula abierta: la posibilidad de que el duque de Alburquerque y el marqués de Santillana se unieran a ellos ${ }^{60}$.

\section{HACIA LA CONSOLIDACIÓN DE LA POSICIÓN ALCANZADA: EL REINADO DE LOS REYES CATÓLICOS}

Tres factores podrían explicar el hecho de que las noticias sobre «el posicionamiento» de Beltrán en las redes nobiliarias disminuyan considerablemente para el reinado de los Reyes Católicos: primero, que el duque pierda protagonismo en la corte influirá en la menor necesidad de acuerdos y alianzas, tan frecuentes en el reinado anterior; segundo, la pacificación del reino y el inicio de un periodo de estabilidad hará que aquéllos sean igualmente innecesarios; por último, la guerra de Granada unió a la nobleza en una empresa común y, aunque continuaron las rencillas y los enfrentamientos personales, todos participaron aunando sus esfuerzos. No obstante, hasta que esa estabilidad mencionada se impuso tuvieron que pasar unos años en los que medió una guerra que enfrentó a Castilla y Portugal. La división del reino, y por lo tanto de la nobleza, por la sucesión del reino se mantuvo hasta el término del conflicto.

Por lo que respecta a Beltrán de la Cueva, curiosamente las acusaciones vertidas contra él por su presunta paternidad de la infanta Juana parecieron disiparse y quedar relegadas en el olvido. Sin embargo, no podemos estimar hasta qué punto permanecían esos rumores en la mente de los monarcas y de los nobles pues, cuando las tropas enemigas cruzaron la frontera, precisamente además por zonas del señorío de Beltrán, las dudas sobre la fidelidad prestada a los nuevos monarcas se pusieron de manifiesto. Según Hernando del Pulgar, pese a que Beltrán de la Cueva acudió a Segovia

\footnotetext{
${ }^{58} 6$ de junio de 1476, en AHN, Secc. Nobleza, Frías, 16/28.

${ }^{59}$ Fue firmado el 11 de enero de 1474, AHN, Secc. Nobleza, Osuna, leg. 417, no 20.

${ }^{60}$ Este pacto fue acordado el 27 de diciembre de 1474, AHN, Secc. Nobleza, Osuna, leg. $417, \mathrm{n}^{\circ} 20$ bis. 
a jurar a Isabel, el duque se posicionó, después del marqués de Villena, del arzobispo de Toledo, del duque de Arévalo, del maestre de Calatrava, del conde de Ureña, del conde de Benavente, del marqués de Cádiz y del conde de Cabra, a favor de los derechos al trono de Juana. Así pues, pese a que el final se inclinaría por el bando de los Reyes Católicos, su asistencia a las tropas portuguesas siguió poniéndose sobre la mesa ${ }^{61}$.

El seguro que los monarcas concedieron a Beltrán en enero de 1475 vendría a demostrar que su situación al principio debía ser incierta, ya que se le prometía seguridad para su persona y bienes. Era en cierto modo el reconocimiento por parte de los reyes de la infidelidad que previamente había cometido contra ellos, su necesidad de controlar las actuaciones del noble, así como el deseo del duque de obtener protección ${ }^{62}$. No obstante, Beltrán participó en la contienda aportando a los monarcas contingentes, a lo que puede responder la capitulación firmada por Beltrán ese mismo año con el mariscal Alfón de Valencia, Gonzalo de Valencia y Juan Porras por la que se ofrecían ayuda mutua con armas y caballos ${ }^{63}$.

Sin embargo, un año después resurgieron las dudas sobre Beltrán y la posición que éste tenía en la corte, lo que determinó que en 1476 se multiplicasen los acuerdos y seguridades firmadas por el duque de Alburquerque con el resto de nobles; los cuales se prestaron rápidamente a colaborar y unirse en la defensa y protección que previamente de nuevo le habrían prometido los monarcas, perdonándole cualquier acción contraria a sus intereses. Como fiadores de las seguridades concedidas al duque a principios de este año encontramos en la documentación a Pedro González de Mendoza, cardenal de España y arzobispo de Sevilla; García Álvarez de Toledo, duque de Alba y marqués de Coria; Pedro Fernández de Velasco, condestable de Castilla; Alonso Enríquez, almirante; Íñigo López de Mendoza, conde de Saldaña y el duque del Infantado y Diego Hurtado de Mendoza, marqués de Santillana ${ }^{64}$.

Contamos igualmente con cartas en las que García Álvarez de Toledo y Alonso Enríquez se comprometían a ser fiadores de la promesa de los reyes de no actuar contra Beltrán. Es significativo que a partir de entonces sea García Álvarez de Toledo quien aparezca reiteradamente en los acuerdos, puesto que había pasado a ser su suegro, aunque lo sería por breve tiempo al morir tempranamente su hija y esposa del duque ${ }^{65}$. No obstante, esto no habría

\footnotetext{
${ }^{61} \mathrm{H}$. PÉRez del Pulgar, Crónica de los Reyes Católicos, pp. 259b y 271a.

${ }^{62} 18$ de enero de 1475 , ACDA, N ${ }^{0} 5, C^{\text {a }} 5, \mathrm{n}^{\circ} 16$.

${ }^{63}$ Establecida el 30 de mayo de 1475 , ACDA, $N^{\circ} 5$, C a 5, n. ${ }^{\circ} 7$. El duque ponía a disposición de esos caballeros 80 lanzas para cuando les fuera menester, durante 30 días, y éstos le ofrecieron al duque 50 , también para 30 días.

${ }^{64}$ Firmadas el 22 de marzo de 1476 encontramos en AHN Diversos Colecciones, leg.

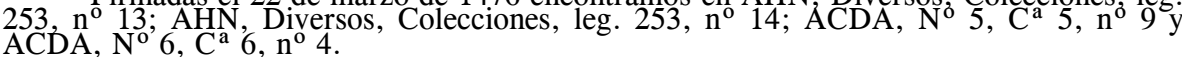

${ }^{65} \mathrm{El}$ duque de Alba, jụnto el almirante de Castilla, se presentará además como fiador de la merced que los reyes hicieron de negar al infante Enrique y a su madre Beatriz las villas de Alburquerque y Ledesma que ahora eran de don Beltrán. ACDA, Estado Alburquerque, $N^{0} 6$, $C^{a} 6, n^{0} 4$ y $N^{0} 5, C^{a} 5, n^{0} 8$. También la seguridad firmada por el cardenal, el marqués de ACDA, $N^{0} 6, C^{a} 6, n^{\circ} 4$. Castilla y el conde de Saldaña con el duque de Alburquerque en

ANUARIo DE ESTUDIOS MEDIEVALES (AEM), 36/2, julio-diciembre 2006, pp. 783-801. ISSN 0066-5061
} 
de suceder hasta tres años después y, además, seguirían siendo consuegros por el matrimonio de sus hijos, Francisco y Francisca. De todos modos, la doble unión por parentesco durante los años que duró el matrimonio de Beltrán y Mencía Enríquez convirtió al duque de Alba en un aliado muy especial del duque de Alburquerque, como lo demuestran los acuerdos que acabamos de citar $^{66}$.

Por otra parte, las alianzas y seguridades de Beltrán beneficiarían a toda su familia, como es el caso de la residente en su ciudad natal de Úbeda, que volvía a tener esperanzas de recuperar lo usurpado por el maestre de Calatrava. Pese a que el duque reclamaba sus derechos desde que los Católicos accedieran al trono, no fue hasta 1476 cuando las promesas de devolución se plasmaron en documentos firmes. En este sentido se firmó la escritura de fianza y seguridad por el cardenal Pedro González de Mendoza y Pedro Fernández de Velasco, condestable de Castilla, a favor de Beltrán y sus deudos ${ }^{67}$. De nuevo el duque de Alba y el almirante se convertirían en garantes de la protección del patrimonio de los Cueva, como hubieran hecho con respecto a las reclamaciones que también le habían interpuesto de Alburquerque y Ledesma, firmando una seguridad por la que los reyes le prometían la devolución de Úbeda, así como sus tierras, heredades, derechos, rentas... que allí tenía ${ }^{68}$.

Precisamente es a partir del cierre de estos pactos cuando la documentación relativa a confederaciones, seguridades y acuerdos de amistad, en los que Beltrán pudiera verse inmiscuido desaparecen. La fidelidad del duque ya había sido totalmente reconocida por los reyes, las concesiones y promesas de devolución estaban asentadas, y la nobleza rebelde, tras la finalización de la contienda sucesoria, era reintegrada y perdonada con el fin de consolidar la estabilidad de la corona. A partir de este momento, Beltrán se centrará en los asuntos más personales y sus tratos con otros nobles serán relativos a intereses particulares, como es el caso de su tercer matrimonio con María de Velasco, en 1479 , que le uniría esta vez a la casa de los Velasco ${ }^{69}$. Igualmente, los enfrentamientos con otros nobles ya no serán determinados por cuestiones políticas, sino por asuntos relacionados con el patrimonio. Tal es el caso de los pleitos interpuestos por el duque de Medina-Sidonia en reclamación de Jimena ${ }^{70}$.

\footnotetext{
${ }^{66}$ Igualmente en acuerdos futuros se observa esta relación entre ambos personajes, por ejemplo en 1477 don Beltrán se ofrecería como garante del pleito homenaje prestado por e duque de Alba al obispo de Segovia, con el compromiso de ayudarle contra quien quisiese atacarle (ACDA, $\left.\mathrm{N}^{\circ} 6, \mathrm{C}^{\mathrm{a}} 6, \mathrm{n}^{0} 4\right)$.

${ }^{67}$ Es significativo que esta promesa se hiciese en el contexto del perdón real dado al duque por las dudas sobre su colaboración con el bando portugués, el 22 de marzo de 1476 . Conservada en ACDA, $\mathrm{N}^{\mathrm{O}} 5, \mathrm{C}^{\mathrm{a}} 5, \mathrm{n}^{\mathrm{o}} 10$

${ }^{68} \mathrm{La}$ seguridad fue expedida también el 22 de marzo de 1476 (traslado de 1765 en ACDA, $\left.\mathrm{N}^{0} 5, \mathrm{C}^{\mathrm{a}} 5, \mathrm{n}^{\mathrm{0}} 16\right)$.

${ }^{69}$ Podemos mencionar, sin embargo, la confirmación el 15 de septiembre de 1478 de la amistad sellada por el duque el 3 de agosto de 1478 y don Pedro de Monroy, en ACDA, $\mathrm{N}^{\mathrm{a}}$ $6, \mathrm{C}^{\mathrm{a}} 6, \mathrm{n}^{\mathrm{O}} 4$.

${ }^{70}$ Véanse, por ejemplo, los documentos conservados en AGS, Registro General del Sello, fols. 43 y 302 . 
Como ya tuvimos ocasión de indicar, en la guerra de Granada la nobleza participaría, bien personalmente, bien enviando contingentes, unida por un objetivo común. De este modo, podemos ver a Beltrán formando escuadra en 1483 con Juan de Guzmán, hijo del duque de Medina-Sidonia, con quien mantenía los pleitos por Jimena como ya hemos mencionado; o en 1485 acompañando a su suegro Pedro de Velasco.

Respecto al enlace la casa de Alburquerque con la de Velasco, hemos de resaltar en la amistad que ya desde los acontecimientos de 1464 había unido a ambos nobles, al menos porque lucharon siempre en el mismo bando y Pedro de Velasco participó en los acuerdos que más podían influir en el futuro de Beltrán en apoyo de éste ${ }^{71}$.

La vinculación del duque de Alburquerque con el de Alba y con el conde de Haro por su segundo y tercer matrimonio no determinó tampoco un alejamiento de los Mendoza, que al fin y al cabo eran todavía parientes suyos por los hijos habidos con Mencía de Mendoza; sobre todo, por el primogénito Francisco, nieto del marqués de Santillana y duque del Infantado.

\section{CONCLUSIONES}

La inclusión del noble en un grupo determinado, la creación de todo un entramado de vínculos de parentesco, de amistad, de clientelismo, era indispensable para el mantenimiento de la situación privilegiada; máxime en tiempos de tempestad política. En el reinado de Enrique IV el ascenso de personajes de bajo origen movilizó a la nobleza, que vio con escándalo como éstos eran premiados por los servicios que prestaban al rey desplazando a los que desde tiempos más remotos habían estado cerca de la figura del monarca. Beltrán de la Cueva fue uno de esos recién ascendidos que hasta tal punto se ganó la confianza regia, que llegó a conocérsele como el privado o favorito del rey. Pero la perpetuación de esa situación no era fácil si sólo se contaba con el respaldo del monarca. Las acusaciones que se hicieron contra él fueron lo suficientemente graves como para que su posición en la corte peligrara, como sucedió a Miguel Lucas de Iranzo, quien, sin llegar a tal situación de crispación, entendió que lo mejor era su exilio a Jaén.

No obstante, Beltrán de la Cueva contó con la ayuda de importantes familias nobiliarias y otros personajes de la corte que garantizaron su permanencia en el círculo más influyente de la aristocracia, aun cuando la situación era muy delicada. Destacamos a los Mendoza, sus más importantes aliados con los que emparentó por vía matrimonial en 1462, a los que se sumaron los Velasco y los Alba, con los que también estableció lazos familiares en posteriores matrimonios.

No obstante, la trayectoria vital del duque de Alburquerque no podría entenderse sólo por sus alianzas y apoyos, puesto que también fue resultado Isabel.

${ }^{71}$ Excepto, recordemos, cuando defendió la devolución de Cuéllar a la todavía infanta 
de los pactos y enfrentamientos acontecidos con sus opositores, a quienes también hemos de considerar en cierta forma como colaboradores del ascenso de Beltrán de la Cueva y de su afianzamiento en el grupo nobiliario. La fidelidad mostrada por el duque a Enrique IV, pese a que le despojó de su máxima conquista, el maestrazgo de Santiago, y pese a sus repetidos cortos exilios, configuraron al noble cortesano, su patrimonio y definieron sus líneas de actuación futuras.

Fecha de recepción del artículo: abril 2006.

Fecha de aceptación y versión final: julio 2006. 